\title{
Comparison of phytoplankton blooms triggered by two typhoons with different intensities and translation speeds in the South China Sea
}

\author{
Hui Zhao ${ }^{1,2}$, DanLing Tang ${ }^{1,2, *}$, Yuqing Wang ${ }^{3}$ \\ ${ }^{1}$ Remote Sensing and Marine Ecology (RSME), LED, South China Sea Institute of Oceanology, Chinese Academy of Sciences, \\ 164 West Xingang Road, Guangzhou 510301, PR China \\ ${ }^{2}$ Graduate University of Chinese Academy of Sciences, 19A Yu Quan Rd, Beijng 100049, PR China \\ ${ }^{3}$ Department of Meteorology and International Pacific Research Center, School of Ocean and Earth Science and Technology, \\ University of Hawaii at Manoa, Honolulu, Hawaii 96822, USA
}

\begin{abstract}
Two phytoplankton blooms in the South China Sea (SCS), triggered by 2 typhoons with different intensities and translation speeds, were compared using remotely sensed chlorophyll $a$ ( $\mathrm{chl}$ a), sea surface temperature (SST), vector wind field, and best-track typhoon data. Typhoon LingLing in 2001 was strong, with a maximum sustained surface wind speed of $59 \mathrm{~m} \mathrm{~s}^{-1}$, and fast-moving with a mean translation speed of $4.52 \mathrm{~m} \mathrm{~s}^{-1}$. Typhoon Kai-Tak in 2005 was weak with a maximum sustained surface wind speed of $46 \mathrm{~m} \mathrm{~s}^{-1}$, and slow-moving with a mean translation speed of $2.87 \mathrm{~m} \mathrm{~s}^{-1}$. The weak, slow-moving typhoon Kai-Tak induced phytoplankton blooms with higher chl a concentrations, while the strong, fast-moving typhoon Ling-Ling induced blooms over a larger area. On average, about 7 typhoons per year affect the SCS, among which $41 \%$ are strong $\left(>50 \mathrm{~m} \mathrm{~s}^{-1}\right)$ and $59 \%$ are weak, while $64 \%$ are fast-moving $\left(>4.4 \mathrm{~m} \mathrm{~s}^{-1}\right)$ and $36 \%$ are slow-moving. We conservatively estimate that typhoon periods may account for $3.5 \%$ of the annual primary production in the oligotrophic SCS.
\end{abstract}

KEY WORDS: Typhoon $\cdot$ Chlorophyll a $a$ Translation speed $\cdot$ Remote sensing $\cdot$ Primary production · South China Sea

Resale or republication not permitted without written consent of the publisher

\section{INTRODUCTION}

Typhoons are violent weather systems over the tropical western Pacific with maximum sustained surface wind speeds (SWS) of $>33 \mathrm{~m} \mathrm{~s}^{-1}$. They can trigger phytoplankton blooms by increasing primary productivity through oceanic eddies and upwelling near their paths (Chang et al. 1996, 2008, Chen et al. 2003, Lin et al. 2003, Zheng \& Tang 2007). In addition to the pre-typhoon depth of the mixed layer and strength of the pycnocline, the response of phytoplankton to typhoon forcing also depends on the translation speed and intensity of the typhoon itself. Previous studies have focused on the effects of individual typhoons on primary production and phytoplankton blooms in the western Pacific and South China Sea (Lin et al. 2003, Zheng \& Tang 2007). Relative effects of intensity and translation speed of typhoons on the water column, and thus on phytoplankton blooms, remain to be investigated.

The South China Sea (SCS, Fig. 1) is the largest marginal sea in the western Pacific Ocean, with a total area of about 3.5 million $\mathrm{km}^{2}$. The East Asian monsoon dominates the SCS, where it largely controls upper ocean circulation (Wyrtki 1961) and thus influences phytoplankton biomass (Tang et al. 2003, 2006). Because most of the SCS belongs to tropical oligotrophic waters with strong underwater irradiance, primary productivity is largely controlled by nutrient availability (Tang et al. 2004a,b). Recent studies have shown that cyclones and typhoons have important effects on chlorophyll a (chl a) concentrations and phytoplankton blooms (Chang et al. 1996, Lin et al. 2003). Zheng \& Tang (2007) showed that Typhoon 


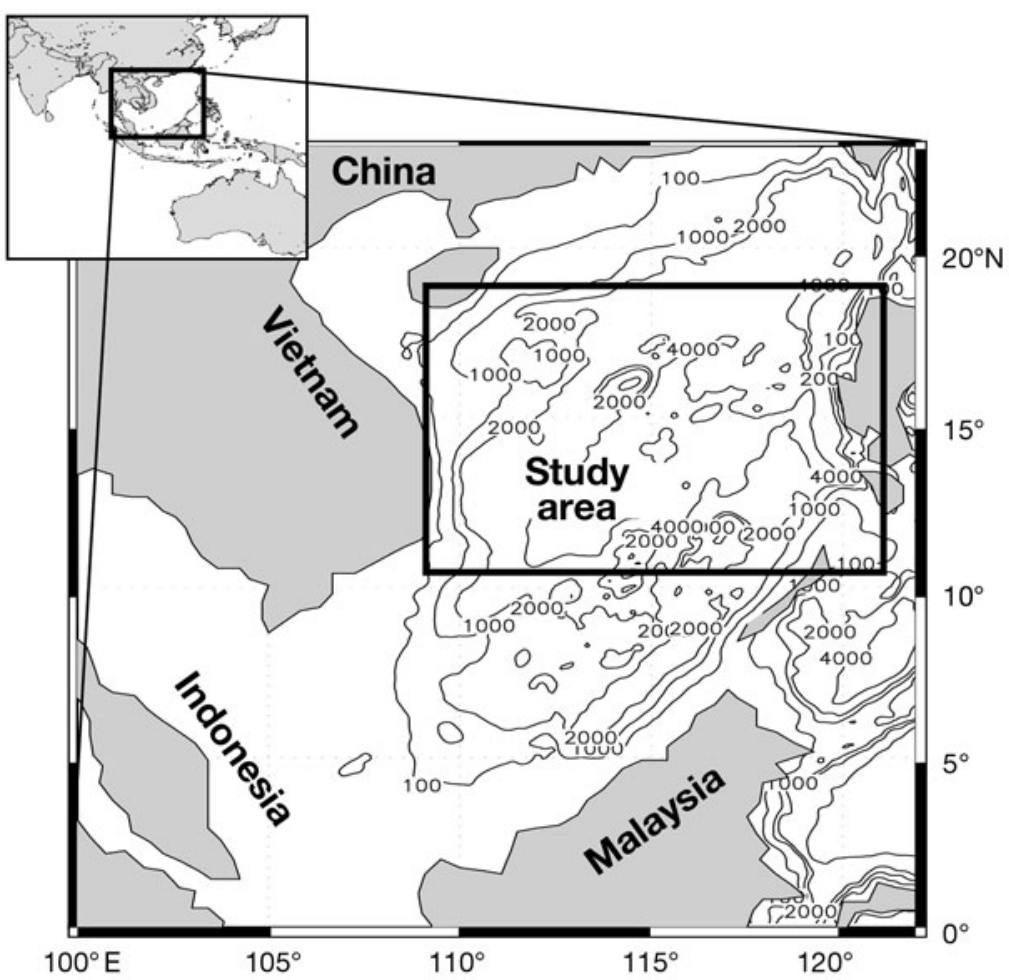

Fig. 1. South China Sea with the study area. Depths in $\mathrm{m}$

Damrey in September 2005 triggered 2 phytoplankton blooms in the northern SCS through upwelling and vertical mixing in the water column and by causing runoff from land, supplying new nutrients to the surface layer. Lin et al. (2003) estimated that tropical cyclone periods could account for 20 to $30 \%$ of the annual new production in the SCS, based on an average of 14 tropical cyclones passing over the SCS per year.

Typhoons can be described as strong or weak according to their intensity (i.e. wind speed and wind stress curls) and as fast- or slow-moving based on their translation speed. Both intensity and translation speed are important factors influencing the upper water column. It has been known for decades that slowmoving or strong typhoons can cause stronger cooling in the upper ocean, due to the duration or the strength of the forcing, than fast-moving and weak typhoons (e.g. Bender et al. 1993). Lowering of the sea surface temperature (SST) can in turn limit the intensity of the typhoon (Emanuel 1999, Wang \& Wu 2004). As a result, slow-moving typhoons cannot generally be very strong, especially when their translation speeds are less than $3 \mathrm{~m} \mathrm{~s}^{-1}$ (Zeng et al. 2007).

The translation speed and intensity of a typhoon may have different effects on phytoplankton biomass and primary production. However, this aspect has not been investigated based on direct observations.
During a typhoon, ship-borne observations on prescribed schedules and cruise routes are very difficult and highly dangerous. Instead, satellite remote sensing is an effective tool to study typhoon-induced phytoplankton variations, because it provides measurements over a large spatial domain, at frequent intervals, and even under severe weather conditions. However, it is difficult to obtain good-quality chl a data during or after a typhoon, because the ocean color remote sensor is easily obscured by heavy clouds and fog. Consequently, we selected 2 rare, successful contemporaneous cases of typhoon observations with good quality chl a images acquired during the SeaWiFS operational period (from September 1997 to December 2005): LingLing (2001, abbreviated L-L) and Kai-Tak (2005, abbreviated K-T) (Table 1). L-L traversed the SCS from east to west over a period of $3 \mathrm{~d}$ between 9 and 12 November 2001 (Fig. 2A). K-T passed over the SCS over $4 \mathrm{~d}$, from 29 October through 2 November 2005 (Fig. 2B). The characteristics of L-L and $\mathrm{K}-\mathrm{T}$ were quite different (Table 1 ). L-L was a strong typhoon with a maximum sustained SWS of $59 \mathrm{~m} \mathrm{~s}^{-1}$, and moved fast at a mean translation speed of $4.52 \mathrm{~m} \mathrm{~s}^{-1}$, whereas $\mathrm{K}$ - T was a weak typhoon with a maximum sustained SWS of $46 \mathrm{~m} \mathrm{~s}^{-1}$ that moved slowly with a mean translation speed of $2.87 \mathrm{~m} \mathrm{~s}^{-1}$. We compared the impacts of the 2 typhoons on phytoplankton blooms and primary production and estimated the contribution of typhoons to the annual primary production in the SCS based on the best-track typhoon data from 1945 to 2005.

\section{DATA AND METHODS}

Satellite products and typhoon data. Daily SST $\left({ }^{\circ} \mathrm{C}\right)$ was obtained from the tropical rain measuring mission (TRMM) microwave imager, which is nearly free of cloud influence over the global tropics. This product has a horizontal resolution of $0.25^{\circ}$ longitude/latitude (Wentz et al. 2000). Surface wind data is based on the microwave scatterometer SeaWinds on the QuikSCAT satellite, which measures surface wind velocity (Liu et al. 2000). We also used monthly mean wind data (Tropical Indian Winds) from the Center for Ocean-Atmospheric Prediction Studies (COAPS) (www.coaps. fsu.edu).

SeaWiFS-derived chl a $\left(\mathrm{mg} \mathrm{m}^{-3}\right)$ and cloud-corrected surface photosynthetically active radiation $\left(\mathrm{PAR}, E_{0}\right.$ : mol photons $\mathrm{m}^{-2} \mathrm{~h}^{-1}$ ), with $9 \times 9 \mathrm{~km}^{2}$ spatial resolution, were obtained from the Distributed Active Archive Center (DAAC) of the US National Aeronautics and 
Table 1. Data on typhoon physical effects and contributions to depth-Integrated Primary Production (IPP) in the South China Sea (SCS). $1 \mathrm{Mt}=10^{12}$ g. EPV: Ekman pumping velocity; L-L: Ling-Ling; K-T: Kai-Tak; SST: sea surface temperature

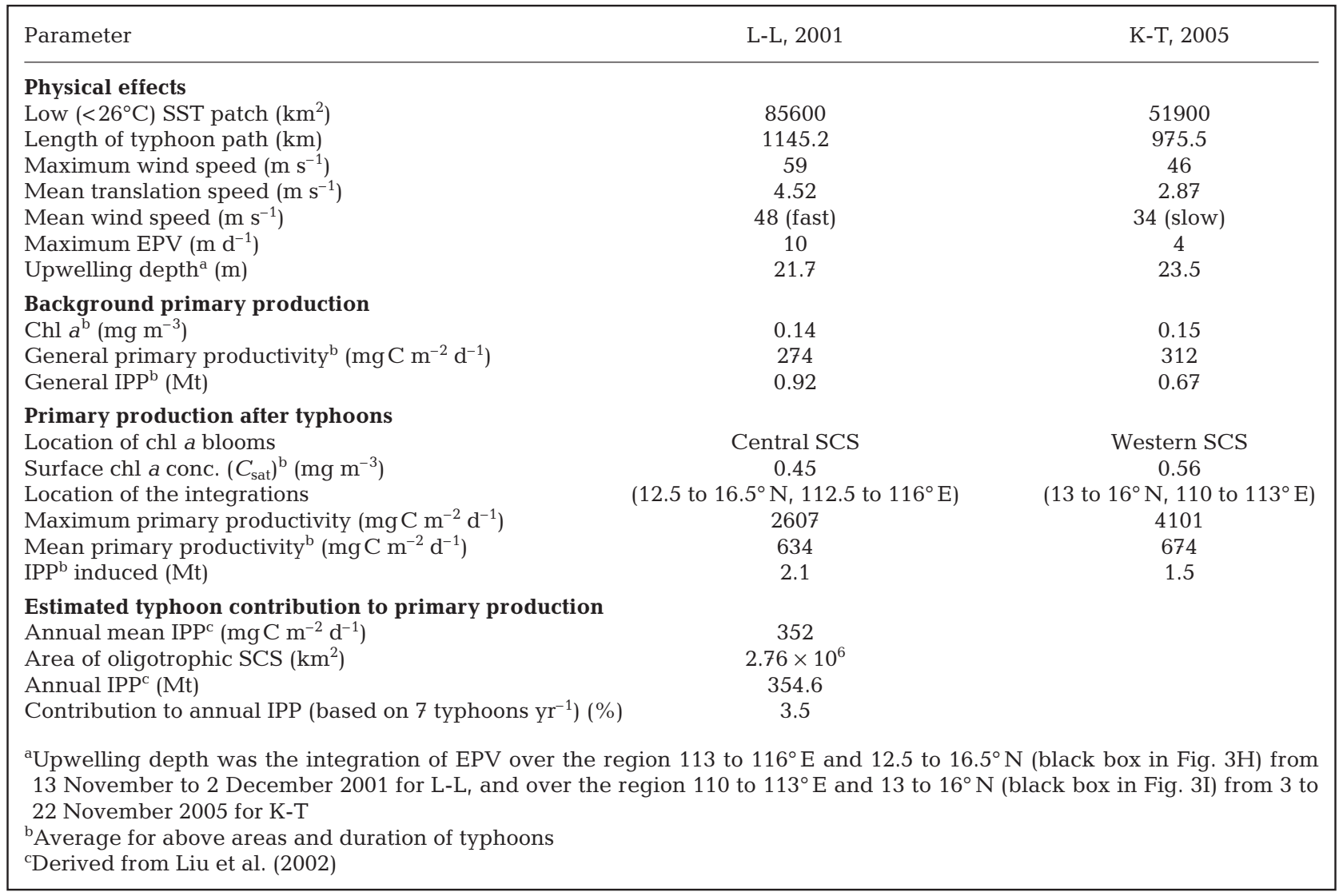

Space Administration (NASA) (http://oceancolor.gsfc. nasa.gov/cgi/level3.pl).

Typhoon data were downloaded from the Unisys Weather website (http://weather.unisys.com/hurricane/ w_pacific/), which uses the best-track typhoon data from the Joint Typhoon Warning Center (JTWC). The data include maximum sustained surface wind (i.e. maximum winds in Table 1) and the longitude/ latitude of the typhoon's center every $6 \mathrm{~h}$. We estimated the translation speed of each typhoon based on the $6 \mathrm{~h}$ positions of its center.

Data processing. Ekman pumping velocity (EPV) is an important index of vertical upwelling movements in the upper ocean. EPV was estimated based on daily and monthly wind data (Stewart 2002, Zhao \& Tang 2007). In order to eliminate the influence of typhoons on chl $a$ and
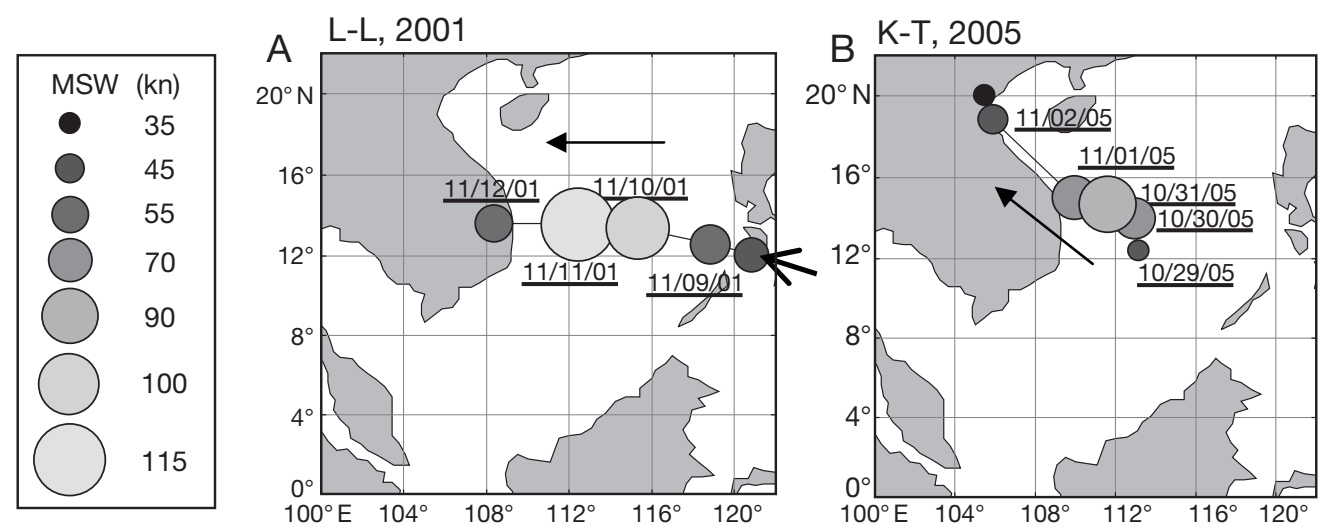

Fig. 2. (A) Track and intensity of typhoons Ling-Ling (L-L) (2001) and Kai-Tak (K-T) (2005) in the South China Sea (SCS). MSW: maximum sustained wind (in knots, $1 \mathrm{kn}=0.514 \mathrm{~m} \mathrm{~s}^{-1}$ ). Dates are given as $\mathrm{mm} / \mathrm{dd} / \mathrm{yy}$ 


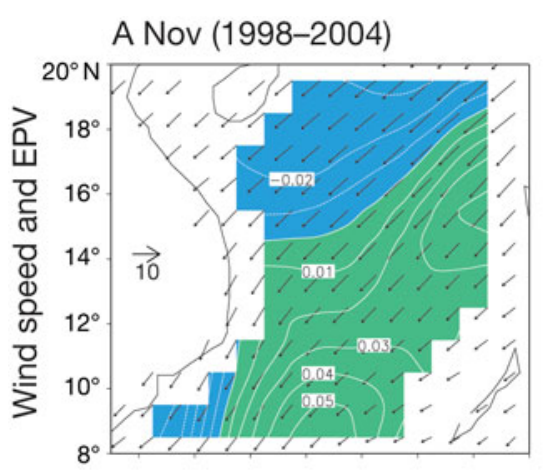

B 10 Nov 2001
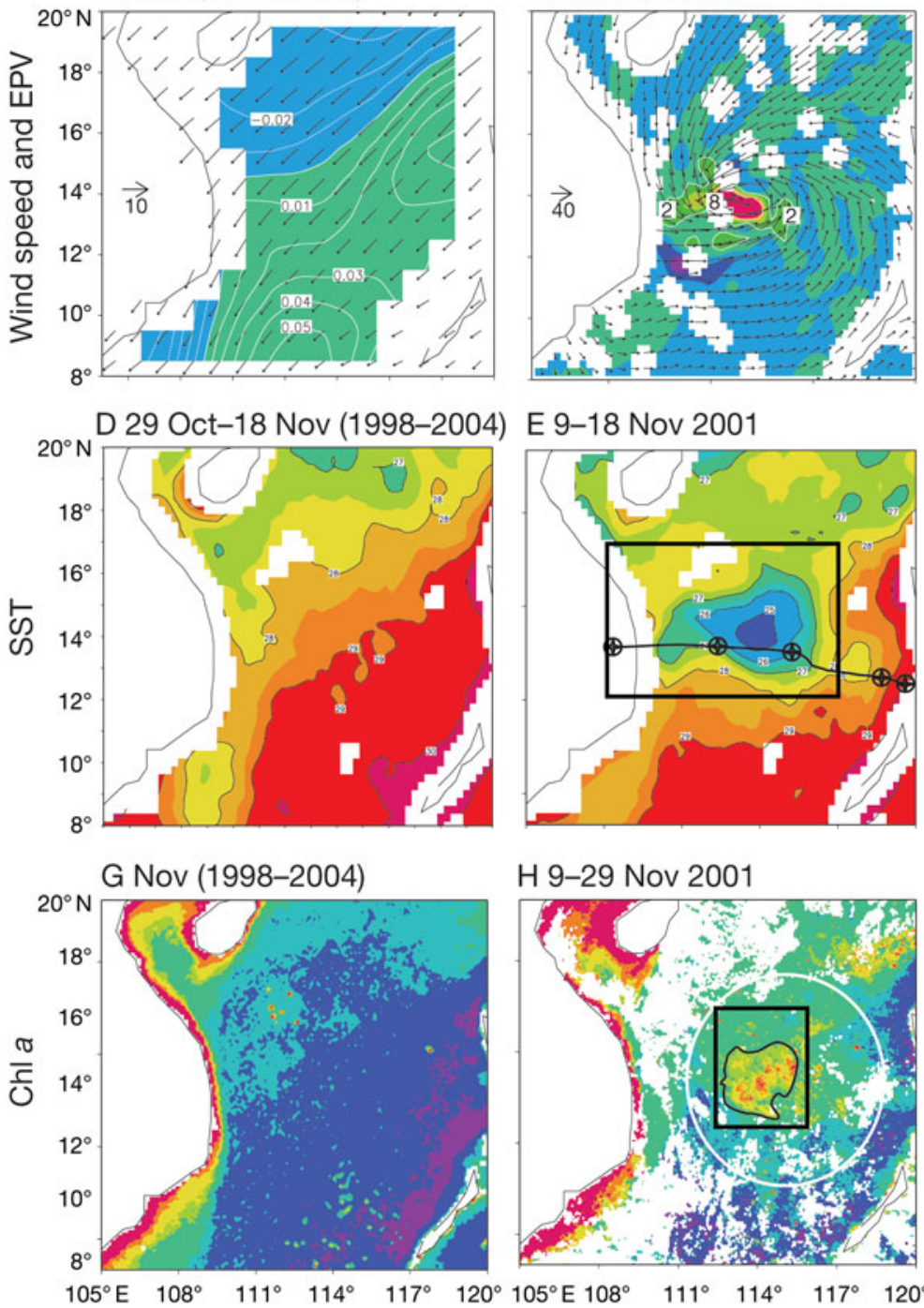

E 9-18 Nov 2001

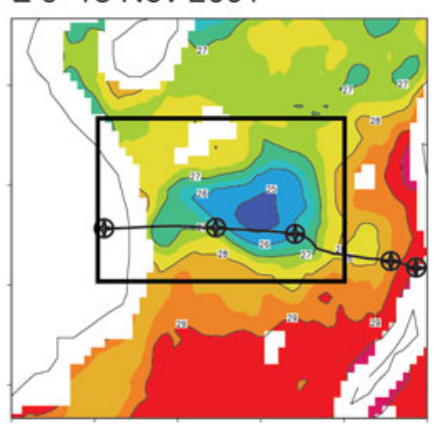

H 9-29 Nov 2001

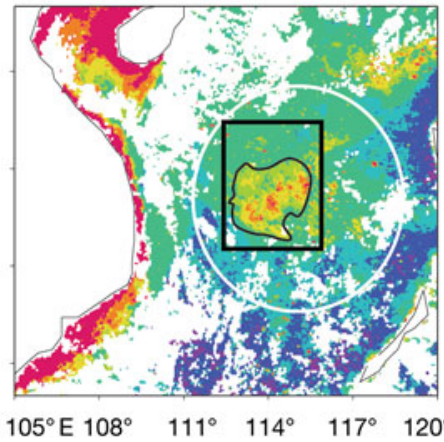

C 30 Oct 2005

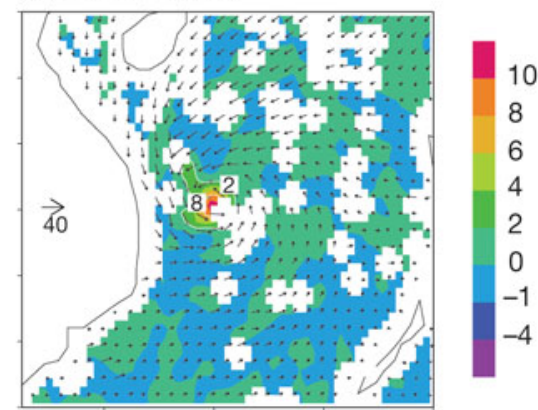

F 29 Oct-7 Nov 2005

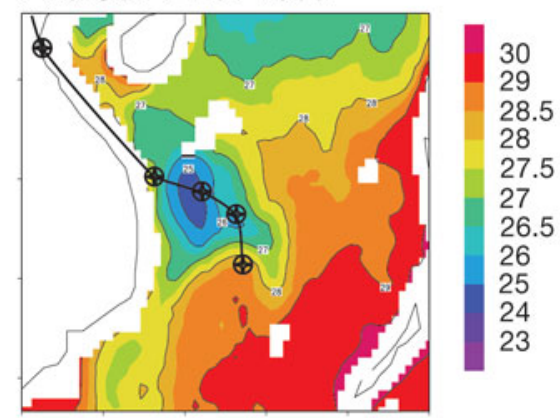

I 29 Oct-17 Nov 2005

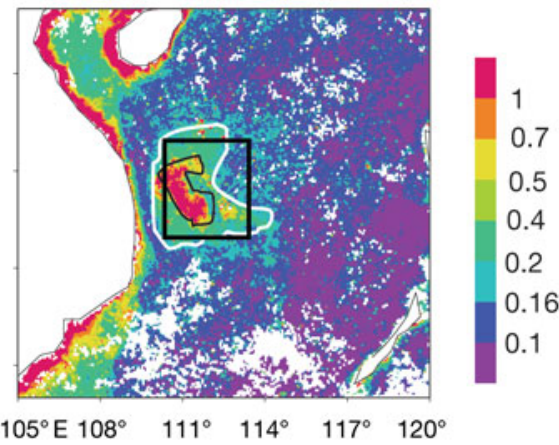

Fig. 3. Climatologies. (A,D,G) (left column) background 1998-2004 (typhoon influence subtracted); (B,E,H) (middle column) Typhoon Ling-Ling (L-L); (C,F,I) (right column) Typhoon Kai-Tak (K-T). (A,B,C) surface wind vectors (arrows represent wind speeds in $\mathrm{m} \mathrm{s}^{-1}$ and their directions) and Ekman pumping velocity (EPV) (color shaded in $10^{-4} \mathrm{~m} \mathrm{~s}^{-1}$ ); (D,E,F) sea surface temperature (SST) $\left({ }^{\circ} \mathrm{C}\right) ;(\mathrm{G}, \mathrm{H}, \mathrm{I}) \mathrm{chl}$ a (color shaded, $\left.\mathrm{mg} \mathrm{m}^{-3}\right)$. Black box in (E) delineates sampling region $\left(108\right.$ to $118^{\circ} \mathrm{E}, 12$ to $17^{\circ} \mathrm{N}$, about $6 \times 10^{5} \mathrm{~km}^{2}$ ) of SST for background climatology and the 2 typhoons; black lines with open circles in (E) \& (F): typhoon paths. Black boxes in (H) and (I) highlight areas of high, typhoon-induced primary production

to match SeaWiFS-derived chl a (between September 1997 and December 2005) with TRMM daytime SST data (available starting 28 November 1997), we removed the typhoon years (2001 and 2005) and the year 1997 when calculating background climatologies (including data for chl a and productivity) for the region. We obtained the background climatologies of wind/EPV, SST, and chl $a$ in October-November by averaging the data from 1998 to 2005 without the typhoon years 2001 and 2005 (Fig. 3A,D,G). Images for the typhoon periods were constructed by averaging data for the calendar days of the 2 chosen typhoons (L-L: Fig. 3B,E,H and K-T 3C,F,I).
The images of surface wind stress/EPV were produced for the day with the strongest sustained SWS for each typhoon (10 November 2001 for L-L and 30 October 2005 for K-T). Time series of satellite data were based on averages over the regions (Fig. 3) and used to investigate temporal changes of the ocean response to typhoon passages (Figs. 4 \& 5).

We estimated depth-integrated primary production (IPP) by using the available SeaWiFS-derived chl $a$, PAR, and SST data, and the vertically generalized production model (VGPM; Behrenfeld \& Falkowski 1997, Behrenfeld et al. 2005, 2006): 
$P_{\text {opt }}=-3.27 \times 10^{-8} \times T^{7}+3.4132 \times 10^{-6} \times T^{6}-1.348 \times$ $10^{-4} \times T^{5}+2.462 \times 10^{-3} \times T^{4}-0.0205 \times T^{3}+0.0617 \times$

$$
T^{2}+0.2749 \times T+1.2956
$$

$$
\begin{gathered}
P P_{\mathrm{eu}}=0.66125 \times P_{\mathrm{opt}} \times\left[E_{0} /\left(E_{0}+4.1\right)\right] \times \\
Z_{\mathrm{eu}} \times C_{\mathrm{sat}} \times D_{\mathrm{irr}} \\
\mathrm{IPP}=P P_{\mathrm{eu}} \times S \times N
\end{gathered}
$$

where $T=\operatorname{SST}\left({ }^{\circ} \mathrm{C}\right), E_{0}=$ sea surface daily PAR (mol photons $\left.\mathrm{m}^{-2} \mathrm{~h}^{-1}\right), Z_{\text {eu }}=\operatorname{depth}(\mathrm{m})$ receiving $1 \%$ of $E_{0}$, $P P_{\text {eu }}=$ daily carbon fixation integrated from the surface to $Z_{\text {eu }}\left(\mathrm{mgC} \mathrm{m}^{-2} \mathrm{~d}^{-1}\right), C_{\text {sat }}=$ sea surface chl $a$ concentration $\left(\mathrm{mg} \mathrm{m}^{-3}\right)$ from satellite data, $D_{\text {irr }}=$ the photoperiod (decimal hours), $P_{\mathrm{opt}}=$ maximum carbon fixation rate within the water column $\left(\mathrm{mgC}(\mathrm{mg} \mathrm{chl} \mathrm{a})^{-1} \mathrm{~h}^{-1}\right), S=$ area $\left(\mathrm{m}^{2}\right)$ used for the vertical integration (for L-L: 12.5 to $16.5^{\circ} \mathrm{N}, 113$ to $116^{\circ} \mathrm{E}$; for K-T: 13 to $16^{\circ} \mathrm{N}, 110$ to $113^{\circ} \mathrm{E}$, i.e. the bold rectangular boxes in Fig. $3 \mathrm{H}, \mathrm{I})$, and $N=$ the number of days. $Z_{\text {eu }}$ was estimated from the empirical relation with chl a in Case I waters (Morel \& Berthon 1989, Cao \& Yang 2002). In Eq. (3), IPP is in Mt $\left(=10^{12} \mathrm{~g}\right)$, representing the total production for a given area. Phytoplankton blooms corresponded to chl a concentration $\geq 0.5 \mathrm{mg} \mathrm{m}^{-3}$.
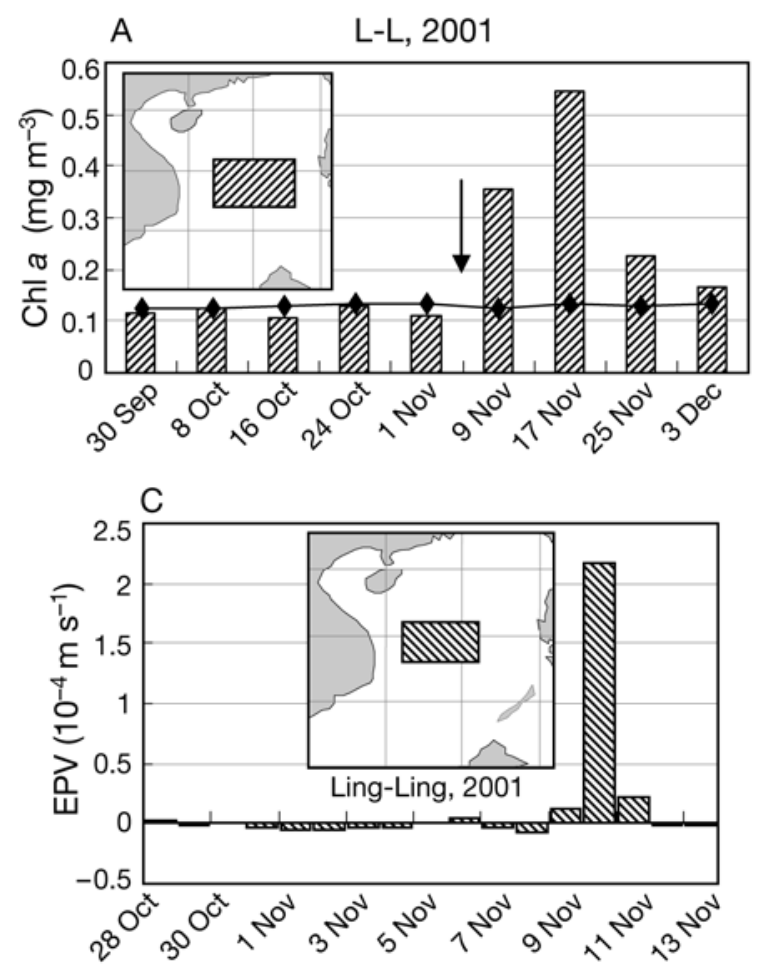

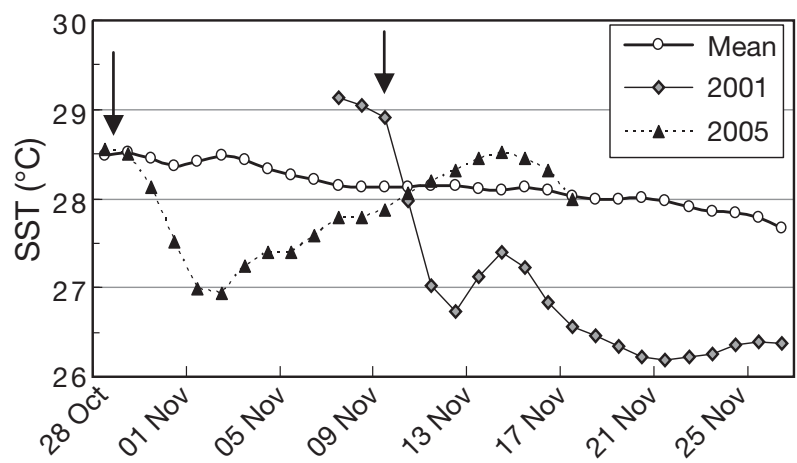

Fig. 4. Time series of sea surface temperature (SST) $\left({ }^{\circ} \mathrm{C}\right)$ for the sampling area (12 to $17^{\circ} \mathrm{N}, 108$ to $118^{\circ} \mathrm{E}$, i.e. box in Fig. 3E) during the 2 typhoons. Mean SST is the average for the corresponding period during 1998-2004, exclusive of 2001, in the same area. Arrows point to the day before each typhoon

\section{RESULTS}

\section{Wind and EPV during the two typhoons}

For convenience, we define a typhoon as strong (weak) when its maximum sustained SWS is higher (lower) than $50 \mathrm{~m} \mathrm{~s}^{-1}$, and as fast- (slow-) moving when its mean translation speed is larger (smaller) than
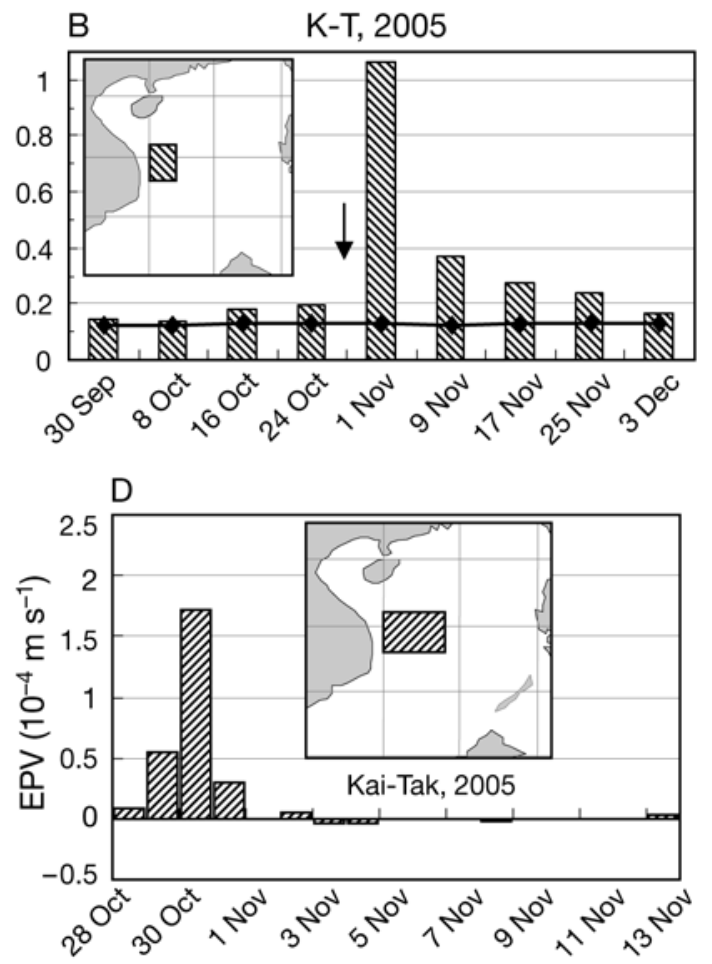

Fig. 5. Chl a concentrations and Ekman pumping velocity (EPV) during typhoons, averaged over the typhoon areas. (A) Chl a concentrations during Ling-Ling (L-L) in 2001; (B) chl a concentrations during Kai-Tak (K-T) in 2005; (C) EPV during L-L in 2001; (D) EPV during K-T in 2005. Black lines: average chl a from 1997 to 2004, excluding 2001; shaded boxes in inserts: areas of integration, arrows: start of typhoons 
$4.4 \mathrm{~m} \mathrm{~s}^{-1}$. Thus, K-T was a weak, slow-moving typhoon (abbreviated WSM K-T), and L-L was a strong, fastmoving typhoon (abbreviated SFM L-L). WSM K-T reached its peak SWS of $46.25 \mathrm{~m} \mathrm{~s}^{-1}$ and its lowest translation speed of $1.13 \mathrm{~m} \mathrm{~s}^{-1}$ when it moved into the western SCS (the white box in Fig. 3F), about 100 to $200 \mathrm{~km}$ from the coastline. SFM L-L reached its peak SWS of $59.09 \mathrm{~m} \mathrm{~s}^{-1}$ and its lowest translation speed of $4.13 \mathrm{~m} \mathrm{~s}^{-1}$ when it was located over the central SCS. The 1998 to 2004 climatology of wind/EPV without typhoon influence (Fig. 3A) showed a low $\left(<10 \mathrm{~m} \mathrm{~s}^{-1}\right)$ SWS and weak upwelling $\left(\mathrm{EPV}<0.4 \times 10^{-5} \mathrm{~m} \mathrm{~s}^{-1}\right)$ in the whole SCS.

The SWS values associated with the 2 typhoons were 2 to 5 times higher than those of the background climatology in the area (Fig. 3B,C). SFM L-L (Fig. 3B) had stronger surface winds than WSM K-T (Fig. 3C), i.e. the peak wind speed was 1.4 times that of WSM K-T and covered a larger area than WSM K-T. Upwelling increased significantly, with EPV values up to $10 \times 10^{-4} \mathrm{~m}$ $\mathrm{s}^{-1}$ near the paths of the typhoons (regions with deep red colours in Fig. 3B,C), which is about 2 orders of magnitude larger than the peak values in the background climatology $\left(<0.1 \times 10^{-4} \mathrm{~m} \mathrm{~s}^{-1}\right.$, Fig. 3A). The region of the high EPV $\left(>10 \times 10^{-4} \mathrm{~m} \mathrm{~s}^{-1}\right)$ induced by SFM L-L (Fig. 3B) in the central SCS (13 to $14^{\circ} \mathrm{N}, 112$ to $\left.114^{\circ} \mathrm{E}\right)$ was broader and achieved higher values than that induced by WSM K-T (Fig. 3C) in the western SCS (13.5 to $14.5^{\circ} \mathrm{N}$ and 111.5 to $112.5^{\circ} \mathrm{E}$ ), which is consistent with the higher surface winds of SFM L-L (Table 1).

\section{Responses of SST}

The SST values between 1998 and 2004 are generally $>28^{\circ} \mathrm{C}$, with a clear northwest-southeast gradient (Fig. 3D). After the typhoons, the SST fell quickly by much more than $1^{\circ} \mathrm{C}$ (white boxes in Fig. 3E, F; Table 1). The low SST $\left(\geq 26^{\circ} \mathrm{C}\right)$ resulting from SFM L-L was located in the central SCS, whereas that caused by WSM K-T was in the western SCS. The area of the low SST patch associated with SFM L-L was larger than that associated with WSM K-T (Table 1). The cooling brought by SFM L-L during the period 12 to 21 November 2001 was also more pronounced than that brought by WSM K-T between 2 and 11 November $2005\left(-1.35^{\circ} \mathrm{C}\right.$ vs. $\left.-0.62^{\circ} \mathrm{C}\right)$. In each case, the sizes of the low SST patches corresponded with the typhoon radius (Fig. 3E,F).

In order to examine temporal changes in the SST, we plotted values averaged over the entire study area of $6 \times 10^{5} \mathrm{~km}^{2}$ (Fig. 1) for the background climatology and the 2 typhoons, respectively. Between 1998 and 2004 the background climatological SST decreased progressively from 28 October to 2 December (Fig. 4), due to solar radiation diminishing with day length. Before SFM L-L, the daily mean SST $\left(\sim 29.1^{\circ} \mathrm{C}\right)$ was about $1^{\circ} \mathrm{C}$ higher than the climatological average $\left(\sim 28.1^{\circ} \mathrm{C}\right)$, and after its passage, the SST dropped rapidly by $2.4^{\circ} \mathrm{C}$ to $26.7^{\circ} \mathrm{C}$ on 12 November $2001\left(1.4^{\circ} \mathrm{C}\right.$ lower than the 1998 to 2004 climatology). Similar results were observed for WSM K-T, but the period of low SST was shorter. The SST for WSM K-T reached a minimum of $26.9^{\circ} \mathrm{C}$ with a peak SST decrease of $1.5^{\circ} \mathrm{C}$ on 2 November 2005 compared to the background climatology (for WSM K-T, the SST on the day before the typhoon, i.e. 29 October 2005, was approximately equal to the SST climatology). The strong decrease in SST induced by SFM L-L is even more obvious when considering that the SST was higher before SFM L-L than before WSM K-T and compared to the SST background climatology. This further stresses the effects of storm intensity and translation speed on the upper ocean.

\section{Biological responses to typhoon passages}

Phytoplankton blooms

Satellite-derived chl a was generally low $(<0.14 \mathrm{mg}$ $\mathrm{m}^{-3}$ ) in the SCS between 1998 and 2004 (Fig. 3G). After the passage of SFM L-L, chl a (mean values for 9 to 29 November 2001) increased quickly to $0.5 \mathrm{mg} \mathrm{m}^{-3}$ in the central SCS (averaged over an area of $\sim 4.6 \times$ $10^{4} \mathrm{~km}^{2}$, black box in Fig. $3 \mathrm{H}$ ). Peak values reached $3 \mathrm{mg} \mathrm{m}^{-3}$ where the typhoon surface wind speed was strongest (Fig. 3B,H). Similarly, chl a (mean values for 29 October to 17 November 2005) increased to $0.5 \mathrm{mg}$ $\mathrm{m}^{-3}$ during the passage of WSM K-T (averaged over $\sim 4 \times 10^{4} \mathrm{~km}^{2}$, black box in Fig. 3I) in an area that coincided roughly with the center of the strongest wind speed, lowest SST and peak EPV. SFM L-L induced a chl a bloom ( $\left.>0.5 \mathrm{mg} \mathrm{m}^{-3}\right)$ in a larger area than WSM $\mathrm{K}-\mathrm{T}$, but the area of chl a concentrations $>1 \mathrm{mg} \mathrm{m}^{-3}$ induced by SFM L-L was smaller than that caused by WSM K-T.

The average temporal change in chl a concentrations over the areas in the black hatched boxes is shown in Fig. 5A,B for SFM L-L and WSM K-T, respectively. The background 1998 to $2004 \mathrm{chl}$ a concentrations (black curves in Fig. 5A,B) were low $\left(<0.2 \mathrm{mg} \mathrm{m}^{-3}\right)$. After the passage of SFM L-L, chl a increased to $0.36 \mathrm{mg} \mathrm{m}^{-3}$ during the first week following the typhoon, and reached $0.54 \mathrm{mg} \mathrm{m}^{-3}$ during the second week. After the passage of WSM K-T, high chl a $\left(>1 \mathrm{mg} \mathrm{m}^{-3}\right)$ was observed during the first week, followed by a decrease to $0.37 \mathrm{mg} \mathrm{m}^{-3}$ during the second week. Concentrations of chl a decreased back to levels that were approximately pre-typhoon about $4 \mathrm{wk}$ after the passage of each typhoon. 
Primary production induced by the two typhoons in the SCS

Based on Eqs. (1), (2) \& (3), we estimated the IPP to be $293 \mathrm{mgC} \mathrm{m}^{-2} \mathrm{~d}^{-1}$ (averaged over the black bold rectangular region highlighted in Fig. 3H) for OctoberNovember in years without typhoon events (Table 1). This is close to the annual mean IPP in the SCS of $354 \mathrm{mg} \mathrm{C} \mathrm{m}^{-2} \mathrm{~d}^{-1}$, calculated by Liu et al. (2002) and Lin et al. (2003). After the passage of the 2 typhoons, the IPP increased to $2607 \mathrm{mgC} \mathrm{m} \mathrm{m}^{-2} \mathrm{~d}^{-1}$ on 14 November 2001 for SFM L-L and $4101 \mathrm{mg} \mathrm{C} \mathrm{m}^{-2} \mathrm{~d}^{-1}$ on 6 November 2005 for WSM K-T (Table 1). Given that the area of the oligotrophic SCS is $2.76 \times 10^{6} \mathrm{~km}^{2}$ beyond the $200 \mathrm{~m}$ isobath (Liu et al. 2002, Lin et al. 2003), the annual IPP is $355 \mathrm{Mt}$ (Table 1). Primary production was $2.1 \mathrm{Mt}$ for SFM L-L and 1.5 Mt for WSM K-T, based on an estimate of $20 \mathrm{~d}$ for the direct and indirect effects from each cyclone. Therefore, SFM L-L and WSM K-T accounted for 0.6 and $0.4 \%$, respectively, of the annual IPP in the SCS (Table 1).

\section{DISCUSSION}

\section{Increase of chl a concentrations during the typhoon events}

Nutrients are crucial to phytoplankton growth in the ocean. Ocean primary production takes place in the euphotic zone, where there is enough sunlight for photosynthesis. In the euphotic zone, however, nutrients are often deficient, and they increase with depth (Levitus \& Boyer 1994). In the SCS, the 2 typhoons exerted strong, curl-induced upwelling (Fig. 3B,C), upper ocean cooling (Fig. 3E,F) and entrainment at sea surface. Thus, the typhoons induced strong upwelling and vertical mixing in their wake, especially at times of strongest wind speed and lowest translation speed (Figs. 2A,B \& 3B,C,E,F), leading to elevated nutrient concentrations in surface waters and fueling phytoplankton blooms.

In the present study, SST values following L-L and K-T at the 2 phytoplankton bloom locations (Fig. 3H,I) indicated that the water masses at the surface may have come from a depth of 60 to $80 \mathrm{~m}$, according to the vertical SST profile in November of Boyer et al. (2006). Nitrate, phosphate and silicate concentrations (in $\mathrm{mol} \mathrm{m}^{-3}$ ) at the above locations reached $\sim 1.5 \times 10^{-3}, \sim 0.94 \times 10^{-3}$ and $7.5 \times 10^{-3}$ at the above depths, compared with surface values of $\sim 1 \times$ $10^{-4}, \sim 2.8 \times 10^{-4}$ and $3.6 \times 10^{-3}$, respectively (Boyer et al. 2006). Thus, the nitrate and phosphate concentrations were 3.3 to 15 times higher at $\sim 75 \mathrm{~m}$ depth than at the surface. Hence, the 2 phytoplankton blooms were likely triggered by high nutrient concentrations in the surface water, caused by typhoon-induced upwelling and mixing.

\section{Comparison of intensity and size of the two chl a blooms}

Previous studies (Lin et al. 2003, Shi \& Wang 2007, Zheng \& Tang 2007) indicated that intensity and translation speed of cyclones are important factors in triggering phytoplankton blooms and in determining the size of bloom patches. In the SCS, an offshore bloom triggered by a typhoon was observed at the location of the typhoon's highest strength by Zheng \& Tang (2007), while Lin et al. (2003) described a large bloom (average surface chl a concentration of $3.2 \pm 4.4 \mathrm{mg}$ $\mathrm{m}^{-3}$ ) during another typhoon's period of slowest motion (translation speed ranging from 0 to $1.4 \mathrm{~m} \mathrm{~s}^{-1}$ ). In the Gulf of Mexico, Shi \& Wang (2007) observed a phytoplankton bloom at the location of a hurricane's highest wind strength and slowest motion. These observations generally correspond to our own.

The radius of strong winds generally increases with the strength of typhoons. Cyclones with a larger radius generally induce large patches of low SST, as suggested by our observations (Figs. 3A-F \& 4) and by results of numerical simulations (Bender et al. 1993). As implied by the typhoon-induced low SST, a strong typhoon (similar to L-L) can cause strong vertical mixing and curl-induced upwelling, leading to high nutrient concentrations in the surface water over a large region. This is consistent with the observation of Lin et al. (2003) that a typhoon-induced bloom patch coincided with the radius of maximum wind, and also consistent with our observation that the size of the phytoplankton bloom was larger for strong L-L than that for weak K-T (Fig. 3H,I, Table 1).

However, K-T induced a more intense phytoplankton bloom (Figs. 3I \& 5B) than L-L (Figs. 3H \& 5A). We propose the following explanation for this: slow translation (long residence time over the area of influence) can enhance mixing and upwelling by a typhoon of a given size and surface wind speed by cooling the surface layer. The slow translation of WSM K-T $\left(\sim 1.13 \mathrm{~m} \mathrm{~s}^{-1}\right)$ likely enhanced its effect on upper-ocean cooling and nutrient injection into the surface layer, whereas the fast translation of SFM L-L $\left(\sim 4.13 \mathrm{~m} \mathrm{~s}^{-1}\right)$ weakened its possible influence, due to a short residence time. Although WSM K-T was a weak typhoon, it exerted a longer lasting influence on the region than SFM L-L. This enhanced the possibly of entrainments (including mixing and upwelling) compared to fast typhoons. The post-typhoon SST images are consistent with this hypothesis, i.e. the low SST patch of $<25^{\circ} \mathrm{C}$ induced by the WSM K-T (Fig. 3F) was roughly equivalent to that induced by SFM L-L (Fig. 3E), based on the averaged SST data after typhoons if neglecting the higher SST over the region before SFM L-L. 
The EPV time series (Fig. 5C,D) also shows that WSM K-T exerted a marked influence on a small area by upwelling and mixing. Although the maximum daily EPV resulting from SFM L-L was stronger than that induced by WSM K-T $\left(2.2 \times 10^{-4}\right.$ vs. $1.7 \times 10^{-4} \mathrm{~m}$ $\mathrm{s}^{-1}$ ) (Fig. 5D), its total Ekman pumping integration, estimated from the area-averaged EPV and the typhoons' translation time (9 to 11 November 2001), was only $21.7 \mathrm{~m}$, compared with up to $23.5 \mathrm{~m}$ (integrated for 28 October to 2 November 2005) by the WSM K-T (Fig. 5C,D). This was due to the fast translation speed (i.e. short residence time over the SCS) of the SFM typhoon. In contrast, the slow speed of WSM $\mathrm{K}-\mathrm{T}$ enhanced entrainment, mixing and upwelling in a small area (the region of high chl $a$ in Fig. 3I), injecting additional nutrients into the surface layer and triggering a high chl a bloom.

\section{Contribution of typhoons to the annual primary production of the SCS}

During 1945 to 2005,425 typhoons (with maximum wind speeds $\geq 33 \mathrm{~m} \mathrm{~s}^{-1}$ ) affected the SCS, i.e. about 7 typhoons per yr on average (Fig. 6A). To estimate the possible contribution of typhoons to the annual IPP in the SCS, we classified the typhoons based on their intensity and translation speed, as we did for SFM L-L and WSM K-T for this study. Overall, $64 \%$ of the typhoons were fast-moving with translation speeds $>4.4 \mathrm{~m} \mathrm{~s}^{-1}$ (Fig. 6B), and $41 \%$ were strong with maximum sustained surface winds $>50 \mathrm{~m} \mathrm{~s}^{-1}$ (Fig. 6C). Based on their intensities, $41 \%$ of the typhoons were similar to SFM L-L, and $59 \%$ to WSM K-T (Table 1, Fig. 6C).

Based on the effects of SFM L-L and WSM K-T on the oligotrophic SCS, it is possible to estimate that typhoons in this region can account for about 3.5\% of the annual IPP. This estimate is rather conservative, because we considered only bloom regions and integrated over only $20 \mathrm{~d}$. However, bloom regions may be larger and high chl a concentrations last longer than $20 \mathrm{~d}$ after typhoon passage. In addition, tropical cyclones with peak wind speeds less than $33 \mathrm{~m} \mathrm{~s}^{-1}$ were not considered in the above estimate.

\section{SUMMARY}

It is widely known that tropical cyclones affect underlying ocean currents and SST. Of the 2 typhoons studied, slow-moving K-T had a longer lasting mixing/upwelling effect on the region around its wake, inducing a stronger phytoplankton bloom. Strong typhoon L-L induced a bloom over a larger area. In general, strong typhoons exert strong surface cyclonic wind stress curls on a large area of the ocean surface, producing strong vertical mixing and upwelling and
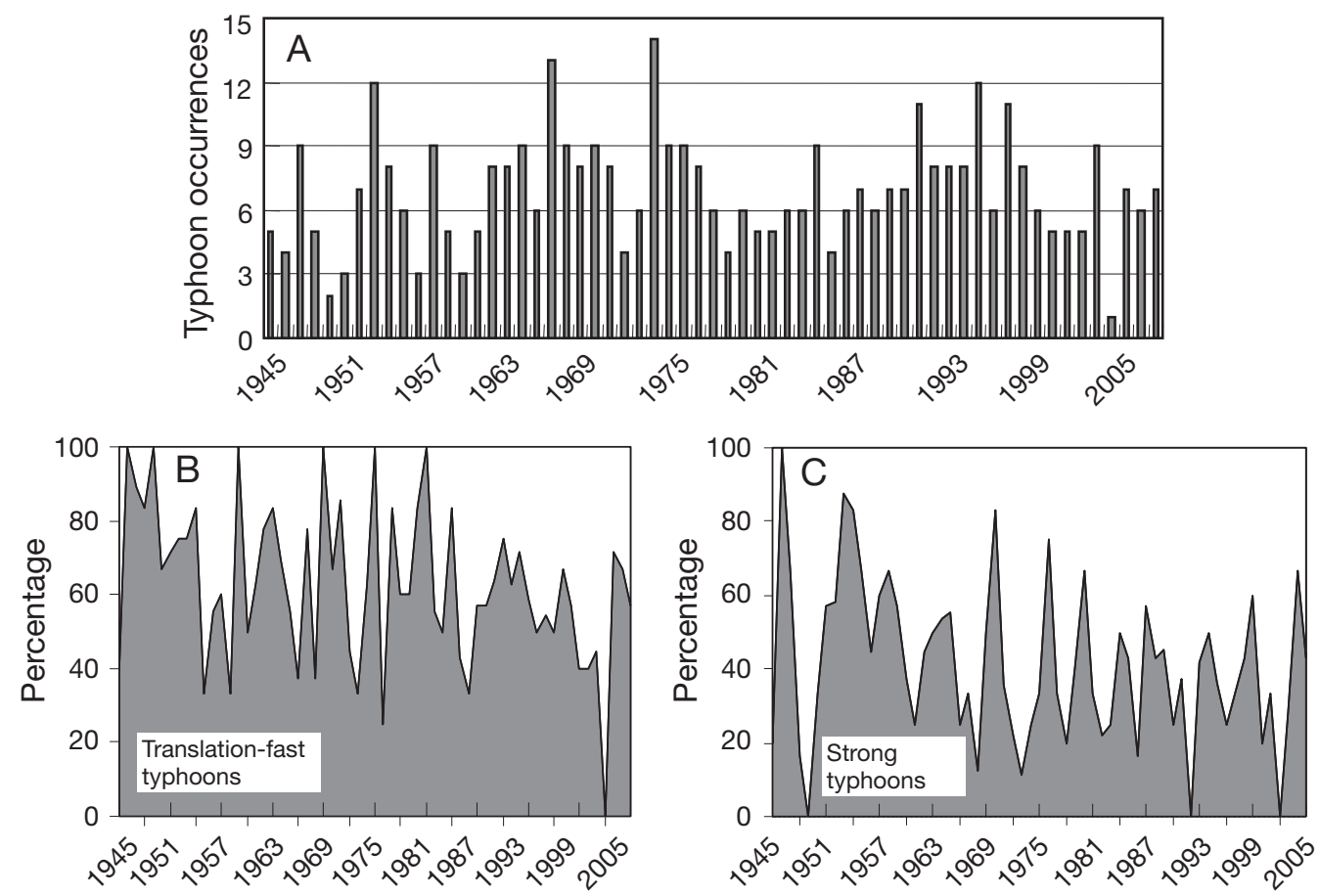

Fig. 6. (A) Annual occurrences of typhoons that affected the SCS during the period 1945-2005, (B) percentage of fast-moving typhoons, (C) percentage of strong typhoons 
bringing up cold and nutrient-rich water to the euphotic zone. A slow-moving typhoon can enhance both cooling of the surface mixed layer and phytoplankton biomass production. As a result, phytoplankton blooms in response to typhoons are closely related to their speeds and intensities, which must be considered when estimating primary production. Based on a classification of typhoons affecting the SCS between 1945 and 2005 according to their intensity and translation speed, we conservatively estimated that they could account for $3.5 \%$ of the annual IPP in the oligotrophic SCS.

Acknowledgements. This study was supported by grants awarded to D.T. by the National Natural Science Foundation of China and the Natural Science Foundation of Guangdong, China (40576053), 'The CAS/SAFEA International Partnership Program for Creative Research Teams' and 'Remote sensing on influence of typhoons on phytoplankton blooms and its contributions to marine ecology for the South China Sea'. H.Z. was supported by 'The Knowledge Innovation Program (07SL011011)' by the South China Sea Institute of Oceanology, CAS. Y.W. was supported by the US Office of Naval Research Grant N0014-21-0532, JAMSTEC (Japan), and NASA through their sponsorship of the International Pacific Research Center at the University of Hawaii. The authors thank Dr. Louis Legendre of Laboratory of Oceanography of Villefranche, France, and Dr. D. X. Wang of SCSIO for their kind suggestions and comments.

\section{LITERATURE CITED}

Behrenfeld MJ, Falkowski PG (1997) Photosynthetic rates derived from satellite based chlorophyll concentration. Limnol Oceanogr 42:1-20

Behrenfeld MJ, Boss E, Siegel DA, Shea DM (2005) Carbonbased ocean productivity and phytoplankton physiology from space. Global Biogeochem Cycles 19:GB1006, doi:10.1029/2004GB002299

Behrenfeld MJ, O'Malley RT, Siegel DA, McClain CR and others (2006) Climate-driven trends in contemporary ocean productivity. Nature 444:752-755

Bender MA, Ginis I, Kurihara Y (1993) Numerical simulations of tropical cyclone-ocean interaction with a high-resolution coupled model. J Geophys Res 98(D12):23245-23263

Boyer TP, Antonov JI, Garcia HE, Johnson DR and others (2006) World Ocean Database 2005. (DVDs) In: Levitus S (ed) NOAA Atlas NESDIS 60, US Government Printing Office, Washington, DC

Cao WX, Yang YZ (2002) A bio-optical model for ocean photosynthetic available radiation. J Tropl Oceanogr 21:47-54 (in Chinese)

Chang J, Chung CC, Gong GC (1996) Influences of cyclones on chlorophyll a concentration and Synechococcus abundance in a subtropical western Pacific coastal ecosystem. Mar Ecol Prog Ser 140:199-205

Chang Y, Liao HT, Lee MA, Chan JW and others (2008) Multisatellite observation on upwelling after the passage of Typhoon Hai-Tang in the southern East China Sea. Geophys Res Lett 35:L03612, doi:10.1029/2007GL032858

Chen CTA, Liu CT, Chuang WS, Yang YJ, Shiah FK, Tang TY, Chung SW (2003) Enhanced buoyancy and hence

Editorial responsibility: Matthias Seaman,

Oldendorf/Luhe, Germany upwelling of subsurface Kuroshio waters after a typhoon in the southern East China Sea. J Mar Syst 42:65-79

Emanuel K (1999) Thermodynamic control of hurricane intensity. Nature 401:665-669

Levitus S, Boyer T (1994) World Ocean Atlas 1994. Vol. 4. Temperature. In: Levitus S (ed) NOAA Atlas NESDIS 4. NOAA, Silver Spring, MD, p 129

Lin II, Liu WT, Wu CC, Wong GTF and others (2003) New evidence for enhanced ocean primary production triggered by tropical cyclone. Geophys Res Lett 30:1718, doi: 10.1029/2003GL017141

- Liu KK, Chao SY, Shaw PT, Gong GC, Chen CC, Tang TY (2002) Monsoon-forced chlorophyll distribution and primary production in the South China Sea. Deep-Sea Res 49:1387-1412

> Liu WT, Xie X, Polito PS, Xie SP, Hashizume H (2000) Atmospheric manifestation of tropical instability waves observed by QuikSCAT and Tropical Rain Measuring Mission. Geophys Res Lett 27:2545-2548

Morel A, Berthon JF (1989) surface pigments, algal biomass profiles, and potential production of the euphotic layer: relationships reinvestigated in view of remote sensing applications. Limnol Oceanogr 34:1545-1562

Shi W, Wang M (2007) Observations of a Hurricane Katrinainduced phytoplankton bloom in the Gulf of Mexico. Geophys Res Lett 34:L11607, doi:10.1029/2007GL029724

Stewart RH (2002) Response of the upper ocean to winds. In: Stewart RH (ed) Introduction to physical oceanography. Texas A\&M University college Available at: http://oceanworld.tamu.edu/resources/ocng_textbook/ contents.html

> Tang DL, Kawamura H, Lee MA, Dien TV (2003) Seasonal and spatial distribution of chlorophyll a and water conditions in the Gulf of Tonkin, South China Sea. Remote Sens Environ 85:475-483

Tang DL, Kawamura H, Doan-Nhu H, Takahashi W (2004a) Remote sensing oceanography of a harmful algal bloom (HAB) off the coast of southeastern Vietnam. J Geophys Res 109, doi:10.1029/2003JC002045

Tang DL, Kawamura H, Van Dien T, Lee MA (2004b) Offshore phytoplankton biomass increase and its oceanographic causes in the South China Sea. Mar Ecol Prog Ser 268:31-41

Tang DL, Kawamura H, Shi P, Takahashi W, Shimada T, Sakaida F, Isoguchi O (2006) Seasonal phytoplankton blooms associated with monsoonal influences and coastal environments in the sea areas either side of the Indochina Peninsula. J Geophys Res 111:G01010

> Wang Y, Wu CC (2004) Current understanding of tropical cyclone structure and intensity changes: a review. Meteorol Atmos Phys 87:257-278

Wentz FJ, Gentemann C, Smith D, Chelton D (2000) Satellite measurements of sea surface temperature through clouds. Science 288:847-850

Wyrtki K (1961) Physical oceanography of the south-east Asian waters. Report No. 2, Naga Report, Scripps Institution of Oceanography, La Jolla, CA, p 1-195

> Zeng Z, Wang Y, Wu CC (2007) Environmental dynamical control of tropical cyclone intensity: an observational study. Mon Weather Rev 135:38-59

Zhao H, Tang DL (2007) Effect of 1998 El Niño on the distribution of phytoplankton in the South China Sea. J Geophys Res 112:C02017, doi:10.1029/2006JC003536

> Zheng GM, Tang DL (2007) Offshore and nearshore chlorophyll increases induced induced by typhoon and typhoon rain. Mar Ecol Prog Ser 333:61-74

Submitted: July 31, 2007; Accepted: March 25, 2008

Proofs received from author(s): July 9, 2008 